\title{
Research on Financial Risks of Robo-Advisor Platforms
}

\author{
Liu, Ruilin ${ }^{1}$ \\ ${ }^{1}$ School of Economics and Management, Beijing Jiaotong University, Beijing, China
}

\begin{abstract}
With the vigorous development of China's Internet finance and financial technology, Roboadvisors have become more and more popular among investors. This new investment and financial management model that relies on Internet platforms, artificial intelligence, quantitative trading technologies will have a greater impact on the capital market once the financial risks caused. How to standardize the Robo-advisory platform, effectively control the financial risks in the investment process and protect the interests of investors is an urgent problem in the Robo-advisory industry. Firstly, this article analyzes the development status of domestic Robo-advisory platforms. Then it puts forward suggestions on how the Robo-advisory industry can face the dual pressures of survival and profit in the context of stricter supervision by analyzing various financial risks and causes of the platform. It aims to promote the sound development of the investment advisory market in the context of financial technology.
\end{abstract}

\section{INTRODUCTION}

As an emerging field combining wealth management and financial technology, Robo-advisory, its core service is to provide customers with products with different combinations and configurations through algorithm models after measuring the individual financial needs, risk appetite and risk tolerance of investors ${ }^{1}$. Then platforms will actively adjust the investment portfolios in the later market fluctuations. Due to the low threshold, high efficiency and digitalization of Robo-advisors, it has been favored by mass investors for a while, especially the nonhigh-net-worth individuals among the "long-tail users".

After a period of transformation and adjustment, China's asset management market will enter a stage of rapid development and diversified competition, with huge development potential. According to data from Chinareport.com, as of the end of 2018, the total scale of China's asset management industry was about 124.03 trillion yuan. According to BCG, the asset management market will reach 184 trillion yuan in 2025 . As a subset of the asset management market, the scale of assets and the number of users of domestic platforms for Robo-advisors business cannot be underestimated. According to Statista estimates, it is estimated that China's Robo-advisory management assets are expected to exceed US $\$ 660$ billion, 100 million users by $2022^{2}$. The large-scale rise of Roboadvisors in the financial technology industry is the most favorable proof of the intelligentization of the financial technology industry. So the prevention of financial risks when Robo-advisors are on the "highway" is even more important.
TABLE 1. ROBO-ADVISOR MANAGEMENT SCALE AND FORECAST

\begin{tabular}{|c|c|c|c|c|}
\hline \multirow{2}{*}{ Year } & \multicolumn{4}{|c|}{ Asset management scale } \\
\cline { 2 - 5 } & World & $\begin{array}{c}\text { Growth } \\
\text { rate }\end{array}$ & China & $\begin{array}{c}\text { Growth } \\
\text { rate }\end{array}$ \\
\hline 2016 & 128 & & 8 & \\
\hline 2017 & 226 & $77 \%$ & 28.9 & $261 \%$ \\
\hline 2018 & 374 & $65 \%$ & 81 & $180 \%$ \\
\hline 2019 & 573 & $53 \%$ & 177 & $119 \%$ \\
\hline 2020 & 815 & $42 \%$ & 316 & $79 \%$ \\
\hline 2021 & 1081 & $33 \%$ & 485 & $53 \%$ \\
\hline 2022 & 1353 & $25 \%$ & 665 & $37 \%$ \\
\hline
\end{tabular}

Data source: Statista

\section{DeVELOPMENT STATUS OF ROBO-ADVISOR}

The business was first seen in the US in the wake of the 2008 financial crisis, with start-ups such as Wealthfront and Betterment among the pioneers. Subsequently, the traditional financial institutions such as capital management companies, consulting companies, Banks and securities companies also gradually involved in this field through research and development or acquisition. ${ }^{3}$. The reason why Robo-advisors can develop rapidly in the U.S. market is that the American-style Robo-advisors business is compatible with the mature financial market and investor needs in the United States. Under the U.S. pension mechanism, investors have formed the concept of long-term passive investment and the U.S. stock market has fluctuated upward as a whole and already has a wealth of passive investment products (ETF) with both long and 
short. Subsequently, the Robo-advisor business has gradually been favored by investors in the UK, Australia, South Korea and other markets.

At present, the Robo-advisory platforms in the Chinese market can be classified and summarized from two perspectives. From the perspective of the development entity, the first category is that independent Internet finance startups rely on portfolio model optimization and data algorithm advantages to mainly engage in Robo-advisory business, such as Money Rubik's Cube, Qian Jing, etc. The second category is the Robo-advisor business developed by traditional financial institutions based on extensive customer resources and massive customer data, such as CMB Capricorn Intelligent Investment, Industrial Intelligent Investment, and Pingan One Account. The third category is that Internet giants rely on their technological advantages and existing customer groups to develop Robo-advisory businesses, such as JD Smart Investment, Ant Financial, and Egg Roll Fund. From the perspective of business models, independent advisory platforms only provide consignment sales of financial products and provide users with suggestions for asset allocation, such as wealth management cubes and blue ocean investment. The integrated wealth management Robo-advisor platforms are generally a business carried out by traditional financial institutions, which not only sells financial products developed by itself, but also sells other financial products, such as Ping An One Account and GF Securities Betaniu. The third type is a configuration consulting platform represented by iFind. This type of platforms select highquality investment targets for users after analyzing realtime market data and various financial indicators.

\section{FINANCIAL RISK AND CAUSE ANALYSIS}

\subsection{Credit risks and their causes}

Compared with traditional financial market activities, the higher virtuality and professional barriers of Roboadvisors relying on the Internet and financial technology will exacerbate the problem of information asymmetry ${ }^{4}$. On the one hand, the Robo-advisory platforms are the dominant information party in terms of funds, investment logic, asset allocation models, artificial intelligence algorithms, etc. Therefore, it may obtain benefits through improper means such as untimely, imperfect information disclosure or even false information. On the other hand, investors' limited information acquisition capabilities and professional information analysis capabilities are more likely to cause credit risks, for example when investors are facing professional financial statements, risk notices, or formatted electronic contracts. The author has confirmed that some Robo-advisory platforms have avoided responsibility and liability for breach of contract in the service agreement.

Based on the above analysis, it is very easy to have moral and adverse selection problems during the operation of Robo-advisory platforms. Chinese investors prefer short-term and high-yield products due to irregular financial markets and immature financial management concepts, so investors are easy to tend to ignore their own risk tolerance and actual market volatility risks. Due to this factor, the platform may attract investors through false information or excessive publicity of high returns. On the one hand, it will mislead investors and make them bear a higher risk portfolio. On the other hand, it may lead to the phenomenon of "bad money driving out good money" in the market ${ }^{4}$. Excessive pursuit of yield may result that a true and reliable platform not getting investors.

\subsection{Technical risks and their causes}

The first type of technical risk is the security risk common to Internet finance. Internet finance relies on computer network information technology and the inherent flaws, security risks of Internet technology will inevitably be transmitted to the main financial services. According to the "CTO Enterprise Information Security Survey Report", the financial industry is the most dependent on the Internet, but more than $50 \%$ of financial companies have no safe investment. At present, most of the Robo-advisory platforms are implemented by mobile phone software. The mobile security company "Love Encryption" selected 10 top-ranked apps in 10 industries for testing. It found that financial application vulnerabilities are the most harmful and security risks are greater among all application categories. Criminals may steal user information by creating Trojan horse viruses or digging system loopholes or directly embezzling user account operations to obtain illegitimate interests ${ }^{5}$.

Another type of technical risk is caused by the design core and the operation method of the Robo-advisory platform. The first is the customer portrait stage. In the traditional investment consulting business, in addition to standardized records of customer information, business personnel can also modify or perfect customer portraits through the personality and behavior characteristics shown in contact with customers. Most of the Roboadvisory platforms collect customers' asset status, risk appetite, risk tolerance, investment experience and other information through questionnaire surveys. On the one hand, the information collected by simple questionnaires is very limited. On the other hand, questionnaire design and grading standards Deviations from the design of the rating formula will affect the true intentions of investors. Secondly, if the Robo-advisory platform uses similar asset allocation models and algorithmic logic, the phenomenon of "concerted people" may appear in actual operations, which will disrupt the financial market order ${ }^{6}$.

\subsection{Legal risks and their causes}

Looking at the market's legal risks from the perspective of separate financial supervision. The operation process of Robo-advisors includes giving investment advice and buying and selling securities, as well as intelligent adjustment of positions based on market fluctuations. Therefore, institutions engaged in Robo-advisory business need to have both investment advisory business licenses 
and discretionary accounts. However, the simultaneous operation of investment consulting business, brokerage business and asset management business by financial companies is expressly prohibited in the Securities Law ${ }^{7}$. Because China's financial market implements separate supervision, the Robo-advisor business involves the vague junctions of the three business areas of the law. In addition, the supervision of business responsibility subjects, artificial intelligence, and algorithm black boxes has not yet been introduced. Therefore, the Robo-advisory market has high legal risks in terms of access and compliance.

Looking at the legal risks of market exit from the $\mathrm{P} 2 \mathrm{P}$ industry. Robo-advisors have many similarities with P2P. The P2P market has experienced successive problems since 2017, which has caused a great impact on the order of the financial market. In the process of market retreat, platforms' promises are fulfilled, but in the later period There have been phenomena of negative payment, malicious defaults and even running away. In addition, the launch of the platform exit system is conducive to ensuring the interests of investors and reducing the panic in the market.

\subsection{Market risks and their causes}

In areas with more mature financial markets such as the United States and Europe, the Robo-advisor business mostly sets investment targets as ETF funds (Exchange Traded Funds) to take into account the liquidity, growth and risk diversification needs of asset allocation. In comparison, the Chinese ETF market started late. As of the end of 2019, there were 284 ETF funds in the market. In terms of types and quantities, the targets that meet the platform investment standards are relatively limited. Nowadays, most of the Robo-advisory platform investment strategies in the allocation of small-cap stocks, bonds, gold, commodities and other assets will also increase the market risk of the portfolio. Besides many Robo-advisory platforms have many overseas assets. On the one hand, there is the allocation of overseas assets Restricted issues. On the other hand, assets also need to bear exchange rate fluctuations, interest rate fluctuations, information and response time delays and other issues.

\subsection{Operational risks and their causes}

The Robo-advisory platform completes the entire business process of investment consulting and asset management through the Internet. Due to the black box algorithm of the platform and the opacity of asset allocation methods, it is easy to cause operational risks. The first risk is the operational risk of the operating platform. Asset allocation recommendations or erroneous trading instructions caused by defects in the platform's product design or information system defects are important sources of operational risk. In addition, improper operations by internal personnel or "insiders" control will have a huge impact on the safety of investors' funds. The second risk is the operational risk of investors. The main customer group of Robo-advisors is still young users with medium and low net worth. In the face of Robo-advisors, which are intelligent investment tools with high professional barriers, they are prone to operational risks. Faced with the form of electronic contract signing online, investors may rashly sign formatted contracts that go against their will. And investors may fail to fully understand the rights and obligations of themselves and the platform, thereby affecting their legitimate rights and interests.

\section{RISK CONTROL RECOMMENDATIONS}

\subsection{Efforts to promote the development of regulatory technology}

The combination of finance and technology is a general trend in the development of the financial industry in the future, but the current regulatory model is still focused on the traditional financial industry, which has obviously lagged behind the development of financial technology. Regulatory technology can better penetrate the many barriers of financial technology through the advancement of regulatory technologies such as big data, blockchain, and artificial intelligence ${ }^{8}$, helping regulators to grasp real-time and accurate market information and respond to predicted risks in a timely manner. However, the current regulatory technology is still in its infancy in various countries, and there are no uniform and specific standards and rules. It is imperative for the state to start building a regulatory technology platform from the aspects of macro policy and top-level design. The development direction of financial technology represented by Robo-advisors is based on algorithms and models, so the optimization of models and algorithms is very important. China can learn from the British regulatory sandbox model and simulate an environment close to the market through the regulatory sandbox, test and optimize algorithms and models, in order to reduce the financial risks caused by Roboadvisors directly entering the market.

\subsection{Improve the legal system}

From the perspective of market access, Chinese laws and regulations should make clear provisions for investment advisory business and asset management business, aiming to solve the current problem of Robo-advisory business involving laws and regulations. With the rapid development of financial technology, it is foreseeable that in the future investment advisory and asset management business will be more closely connected. Traditional separate operation and separate supervision may not be suitable for the current market environment. When Roboadvisors were born in the United States with uniform and clear legal regulations, the United States has clearly stipulated in the "Investment Consultants Act" of 1940 that anyone who obtains an investment consultant license can simultaneously engage in asset management and financial services. China can also unify investment advisory and asset management business licenses with reference to the US approach. 
In addition, clarifying the ownership of responsibilities is also an important part of improving the legal system. On March 25, 2016, at the inaugural meeting of the China Internet Finance Association, Pan Gongsheng, the vice governor of the People's Bank of China, emphasized: "For Internet finance, penetrating supervision should be implemented. At the same time, functional supervision should be implemented. Regulatory loopholes, eliminate regulatory gaps, and achieve full coverage of financial risk supervision. ${ }^{9} . "$ In the process of improving the legal system, the responsible body in the Robo-advisor business should be clarified. The core of Robo-advisor is algorithms and procedures, which are only provided by financial institutions. A financial service cannot be a legal subject. Therefore, the relationship between investors and Robo-advisory platforms should be investors and financial institutions that hold investment advisory and asset management business licenses. Finally, how to determine the responsible parties within the platform needs to be clearly defined by the law.

\subsection{Promote investment education and construct ways to protect rights}

Investor education should not simply stop at "the market is risky and investment needs to be cautious". While cultivating investors' risk awareness, we should increase the cultivation of investors' investment philosophy, especially Robo-advisor customers are mostly 25 For lownet-worth groups in their 30s. Therefore, the author suggests that investor education can be introduced into the classroom. The Robo-advisor business is mainly aimed at long-tailed people with medium and low net worth. This group of people may not have been exposed to investment consulting and asset management before and most of them are still in the short-term investment stage pursuing excess returns. Most people do not have long-term investments. And the awareness of the allocation of largescale assets, and China's current securities market is not mature enough, may cause investors to suffer huge losses in the process of short-term operations. Especially in the environment of rigid redemption in China, investors want excess returns but do not want to bear the risks brought by high-risk allocations. Therefore, strengthening the education of investors is of utmost importance. The society should spread the basic knowledge of the financial market to the people with investment needs through various channels.

In addition, Robo-advisors are still in a period of chaotic industry standards. There are many platforms that use the name of Robo-advisors to engage in illegal and illegal businesses such as illegally recommending stocks or illegally selling funds ${ }^{10}$. Investors may not be able to safeguard their legal rights effectively due to lack of rights protection channels. It is recommended that the regulatory authorities issue rights protection guidelines or provide rights protection guidance to minimize financial risks to society as much as possible.

\subsection{Speed up the training of financial technology talents}

Robo-advisors urgently need relevant talents from both the regulatory level and the platform construction level. In the financial aspect, practitioners are required to be familiar with the characteristics and risk characteristics of various financial products and to master various asset allocation models. In the aspect of legal talents, practitioners are required able to fully understand the relevant laws and regulations to ensure that the Roboadvisory platform can operate in compliance with laws and regulations. In terms of artificial intelligence, practitioners need to be able to do big data analysis, machine learning and algorithm optimization and other core content and explore the actual market conditions in China Robo-advisor business model. In short, the future development of Robo-advisors requires talents in finance, big data, artificial intelligence, law and other cross-fields ${ }^{11}$. It requires both a solid theoretical foundation and strong practical application capabilities. Platforms should focus on information security, platform intelligence and risk control and make improvements in such areas. Therefore, it is necessary to promote the development of financial technology and regulatory technology by strengthening talent training.

\subsection{Special periodic review of Robo-advisor business}

Countries with more mature Robo-advisors, such as the United States and the United Kingdom, have already carried out a comprehensive special review of their platforms try to control the financial risks of Roboadvisors. The experience of European and American countries has proved that special review work can limit the technical risks and potential risks in Robo-advisory products. In view of the current situation of the Roboadvisory market in China, I recommend that the government can start from the business process and conduct "full- business chain" review. At the stage when the customer signs the service agreement and the risk notification letter, the focus is to review whether the formatted contract of the Robo-advisor platform has fulfilled the risk notification obligation and whether there are unreasonable platform exemptions. In the stage of collecting customer information and generating customer portraits, the focus is on whether the questionnaire design is reasonable and whether the customer risk rating algorithm is complete. In the target asset selection stage, the focus is to examine whether the asset allocation model selection is reasonable and whether there are loopholes in the artificial intelligence algorithm. In the later stage of investment strategies adjustment, the focus is to examine whether there is unreasonable position adjustment and frequent transactions to earn commissions. In addition, it is necessary to proceed from the outside of the market to regularly review the authenticity and accuracy of platform information disclosure and promotional content. 


\section{SUMMARY}

This article first analyzes the business characteristics of the Robo-advisor platform and its development status at home and abroad. After that, the author analyzed the important risk points of Robo-advisors business from five aspects: credit risk, technical risk, legal risk, market risk and operational risk by combining the business process and internal logic of Robo-advisors. Finally, this article puts forward suggestions for improving the supervision and legal system, strengthening investor protection, and accelerating the training of financial technology talents in order to promote the sound development of Roboadvisory business and give full play to its function of inclusive finance.

\section{REFERENCES}

1. Wei Zhaochun, $\mathrm{Xu}$ Jiangang, "The theoretical framework and development response of intelligent investment advisors," Wuhan Finance , pp. 9-16, April 2018.

2. Accenture, "Robo-advisor in China," Software and integrated circuits, pp. 66-77, April 2019.

3. Jiang Haiyan, Wu Changfeng, "The development status of robo-advisors and regulatory suggestions," Securities Market Herald, pp. 4-10, December 2016.

4. Hou Dongde, Zhang Ran, "The generation logic and governance strategy of intelligent investment credit risk," Journal of Northwestern Polytechnical University, pp. 85-94, 2019.

5. Jiang Huiyu, "Research on System Prevention of Technical Risks of Robo-Advisor," Jinan Journal, pp. 48-58, September 2019.

6. Chen Huihua, "Research on Application Risk Governance of Robo-Advisor Algorithm from the Perspective of Supervision," Journal of insurance professional college, vol. 34, pp. 70-74, June 2020.

7. $\mathrm{Xu} \mathrm{Li}$, "Research on the Legal Risks and Countermeasures of Robo-Advisor," Hainan Finance, pp. 43-50, September 2019.

8. He Shujian, "FinTech supervision based on penetrating perspective," New Business Weekly, pp. 30-32, February 2018.

9. Yu Wenju, "The development status of China's roboadvisors and its legal supervision," Hainan Finance, pp. 61-66, June 2017.

10. Chen You, "Research on innovation of Internet Finance in intelligent Wealth management," Rural Finance Research, pp. 33-38, October 2018.

11. $\mathrm{Xu}$ Huizhong, "Regulatory difficulties and countermeasures of China's robo," Financial Development Research, pp. 86-88, July 2016. 